\title{
Empirical Analysis of RSI Based on Vocational Education Sector of Listed Companies
}

\author{
Fang $\mathrm{Yu}^{1,2}$ \\ ${ }^{1}$ School of education, Tianjin University, Tianjin 300072, China \\ 57401476@qq.com \\ ${ }^{2}$ Mathematics and Information Science Department, Guangxi College of Education, Nanning 530023, \\ Guangxi, China \\ 57401476@qq.com
}

Keywords: Vocational education sector, RSI, Empirical analysis

\begin{abstract}
The paper tests the RSI expert system of securities trading software based on the real and open data from securities vocational education sector through the statistical empirical analysis. It makes empirical analysis of RSI anti trend index with annual net profit rate, rate of return and win rate as the management objective and the theory of mathematical statistics as the research basis, and obtains the result that the annual rate of return and net profit margin of RSI expert system were $44.4 \%$ and $44.3 \%$ of Shanghai Composite Index. $100 \%$ win rate and 4.76 times annual rate of return of annual interest rate on bank deposits provide a safe investment plan for investors. This result is obviously acceptable.
\end{abstract}

\section{Introduction}

In the global financial transactions, technical analysis is an important ad more popular method. The software expert system often used in technical analysis method is necessary. Huang et al. studied average line expert system MA and anti trend expert system RSI [1] and concluded that besides annual transaction times, RSI expert system was overall superior to MA expert system in the win rate, annual rate of return and net profit rate. They also studied anti tread expert system RSI, BIAS, KDJ and W\&R [2-3] and concluded RSI expert system was the best in the annual rate of return and net profit margin based on test results and W\&R was the worst. RSI net profit margin and annual rate of return were approximately 5 times better than W\&R. And BIAS expert system reached up to 98.54\% in the success rate and $W \& R$ reached up to 7,658.40 in annual transaction times. Now we make empirical analysis with annual net profit rate, rate of return and success rate as the management objective, the vocational educational sector of listed companies as the sample, and RSI expert system as the analytical tool.

RSI (Relative Strength Index) transaction index was mentioned and given the corresponding formula by American J. Welles Wilder JR in the book New Concepts in Technical Trading System in 1978. Later, RSI index was widely applied to trade in commodities, futures and securities.

RSI (Relative Strength Index) mathematical formula [4]:

$$
\begin{aligned}
R S I & =\frac{100 \times R S}{1+R S} \\
R S & =\frac{\text { Average Rise Point in i days }}{\text { Average Dropped Point in i days }}(i=1,2, \mathrm{~L} n)
\end{aligned}
$$




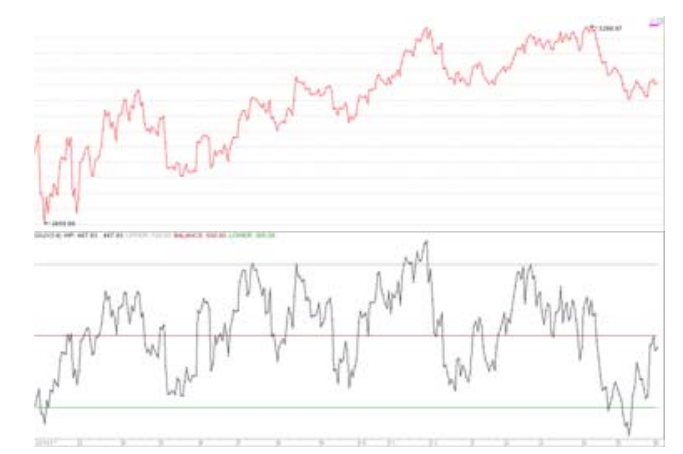

Figure 1 Shanghai Composite Index

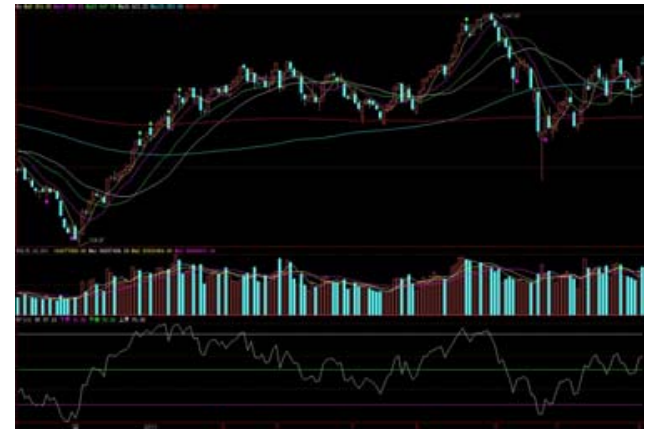

Figure 2 RSI Expert System

\section{Empirical Analysis Based on RSI expert system (shown in figure 2)}

Experiment and Results

(1) Experimental procedures

Expert system RSI is formulated based on the rule by Welles Wilder. The buying and selling rule is: buying when RSI (14) varies from 0 to 20 or from 50 to 80, selling RSI (14) varies from 80 to 100 , and waiting and seeing when RSI (14) varies from 20 to 50

Source code of RSI expert system

N1 110014

LL 04020

LH 6010080

LC: = REF (CLOSE, 1);

RSI:SMA(MAX(CLOSE-LC,0),N1,1)/SMA(ABS(CLOSE-LC),N1,1)*100,colorwhite;

ENTERLONG: CROSS (RSI, LL);

EXITLONG: CROSS (LH, RSI)

(2) Experimental platform: great wisdom securities information platform V5.99 version

(3) Experimental parameters: to open a position once or close all positions when conditions are met. Transaction costs take $0.5 \%$.

(4) Experimental sample: daily data of vocational education sector (March 2016 through April 2017)

(5) Experimental process, time and results:

Table 1 Test Results Based on RSI Expert System

Test method: technical index - RSI (14)

\section{System Test Settings}

Test time: March $1^{\text {st }}, 2016$ to April $11^{\text {th }}, 2017$, excluding forced liquidation

Tested shares: 25 in total Initial inputs: 4, 000 Yuan

Buying terms:

One of the following groups is met:

1. The following conditions are simultaneously met

1.1 Technical index: RSI (14) index line RSI crossing the lower bound (daily line)

When conditions are met: buy with all funds at the closing price based on the central price

When signals occur constantly: refuse to continue to buy

Selling terms: no selling conditions

Liquidation terms: (close a position according to the closing price)

Index selection: technical index: RSI (14) index line RSI breaking the upper bound (daily line)

\section{System Testing Summary}

System testing summary

Number of tested shares: $\quad 25$

Annual rate of return: $\quad 8.33 \%$ Annual transaction times: 8.31 


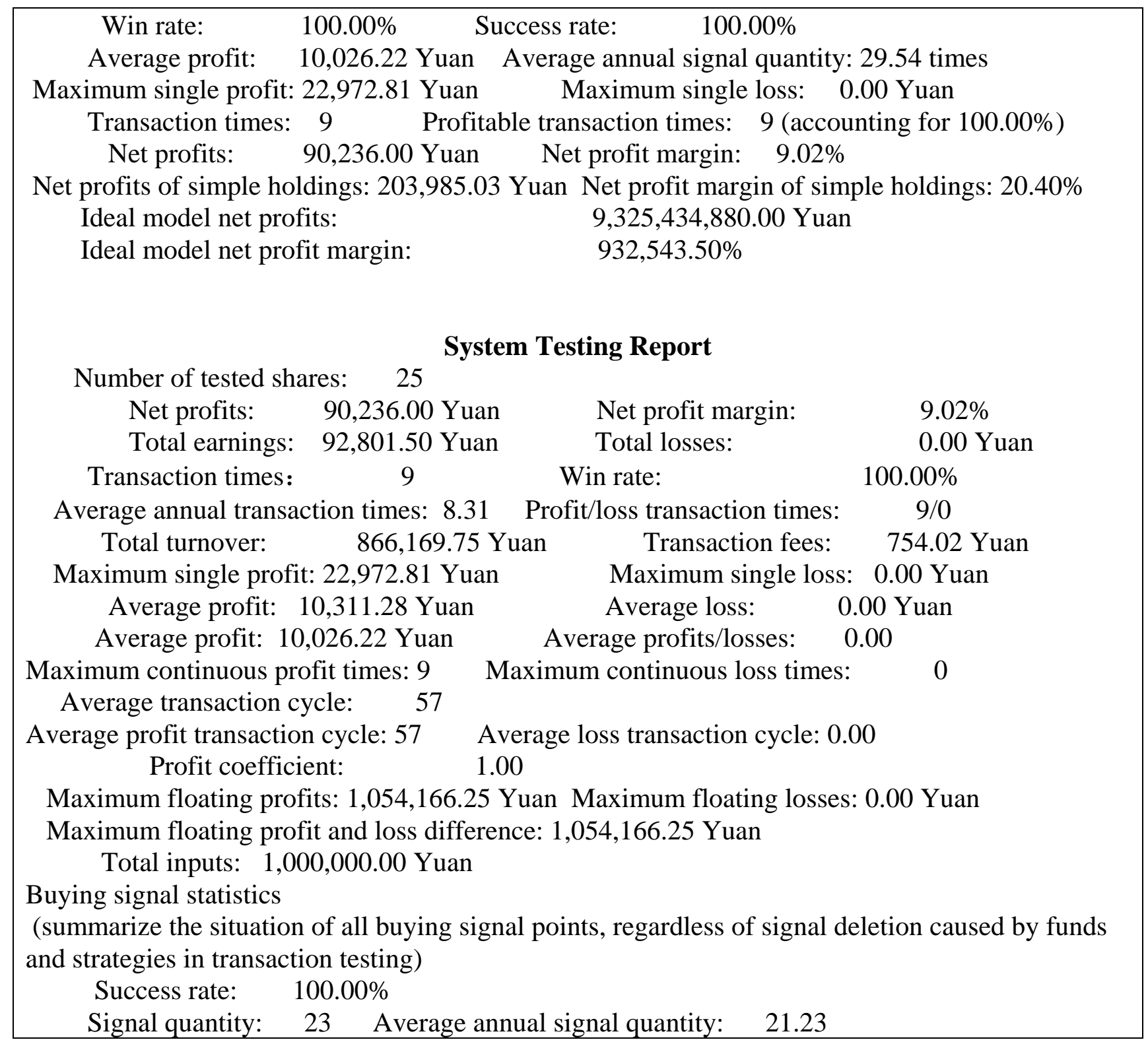

Analysis of Results

Table2 Comparative Analysis Sheet

\begin{tabular}{|c|c|c|c|c|}
\hline & Win Rate & $\begin{array}{c}\text { Annual Rate of } \\
\text { Return }\end{array}$ & Net Profit Margin & $\begin{array}{c}\text { Annual } \\
\text { Transaction } \\
\text { Times }\end{array}$ \\
\hline $\begin{array}{c}\text { RSI Expert } \\
\text { System }\end{array}$ & 100 & 8.33 & 9.02 & 29.54 \\
\hline $\begin{array}{c}\text { Shanghai } \\
\text { Composite Index }\end{array}$ & & 18.76 & 20.33 & \\
\hline $\begin{array}{c}\text { Ratio of RSI } \\
\text { Results and } \\
\text { Shanghai } \\
\text { Composite Index } \\
\text { Results }\end{array}$ & $44.4 \%$ & $44.3 \%$ & \\
\hline
\end{tabular}




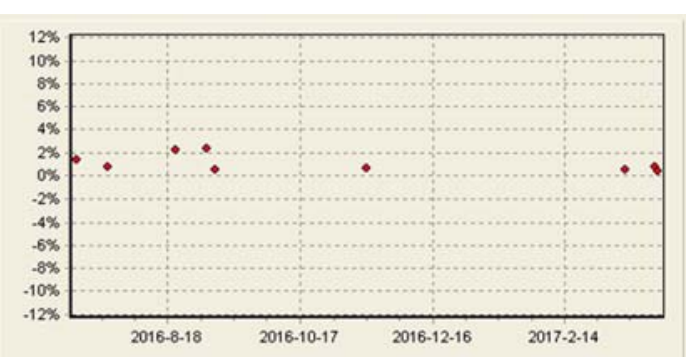

Figure 3 Annual Transaction Times

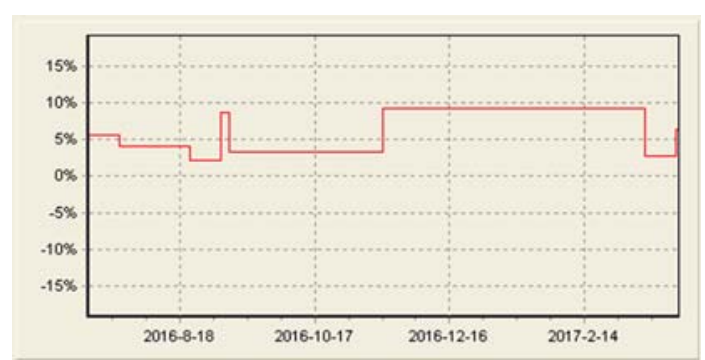

Figure 4 RSI Yield Curve

\section{Conclusion}

The paper analyzes the practicability of RSI expert system with the win rate, annual rate of return and net profit rate that investors pay the most attention to as the management objective [6]. The result that the annual rate of return and net profit margin of RSI expert system were $44.4 \%$ and $44.3 \%$ of Shanghai Composite Index shows that the investment in vocational education sector under the guidance of RSI expert system cannot outperform the market index. And RSI expert system with $100 \%$ win rate provides a safe investment plan for investors. The investment plan is obviously popular with the investors who hate risks. The result that $8.33 \%$ annual rate of return is 4.76 times annual interest rate on bank deposits is obviously considerable. To sum up, it is a risk-free plan that the investment in vocational education sector is guided through RSI expert system. According to the image indicator of RSI expert system shown in figure 1 and 2, the long-term holdings are a magic weapon to outperform the market index.

\section{Acknowledgement}

This research was financially supported by the Education Department of Guangxi Province (NO.KY2016YB579), and scientific research projects of Guangxi College of Education in 2015 (NO.A2015001,NO.B2015001,NO.B2015006), and 2017 Key Program for Education and Teaching Reform of Guangxi College of Education (NO.XJJG17A09).

\section{References}

[1] H. P. HUANG, P. WANG: "Discussions on Securities Software Expert System MA and RSI”, Advanced Materials Research, 798-799 (2013)757-760

[2] P. WANG, H. P. HUANG: “On the W\&R and RSI Expert Systems of Securities Software”, Applied Mechanics and Materials, 433-435(2013)1685-1688

[3] H. P. HUANG, P. WANG: "Analyses on W\&R and BIAS Expert System of Stock-market Software”, Applied Mechanics and Materials, 433-435(2013)2391-2394

[4] Information on http://en.wikipedia.org/wiki/Relative_strength_index

[5] WANG Pin "RSI Investment Decision-Making Based on Consolidation Market” Journal of Quantitative Economics 01 (2012) 25-29

[6] HUANG Hai-ping, WANG Pin “Discussions on Securities Software Expert System MA and RSI” Advanced Materials Research 798-799 (2013) 757-760 